\title{
Soluble Tumor Necrosis Factor Receptor 1 Is Associated with Glomerular Filtration Rate Progression and Incidence of Chronic Kidney Disease in Two Community-Based Cohorts of Elderly Individuals
}

\author{
Axel C. Carlsson ${ }^{a, c}$ Lina Nordquist ${ }^{d}$ Tobias E. Larsson $^{b}$ \\ Juan-Jesús Carrerob ${ }^{b}$ Anders Larsson ${ }^{e} \quad$ Lars Lind $^{f} \quad$ Johan Ärnlöv ${ }^{d, g}$ \\ ${ }^{a}$ Division of Family Medicine, Department of Neurobiology, Care Sciences and Society, \\ Karolinska Institutet, Huddinge, ${ }^{\mathrm{b}}$ Department of Clinical Science, Intervention and Technology, \\ Karolinska Institutet, Stockholm, 'Department of Medical Sciences, Cardiovascular \\ Epidemiology, ${ }^{\mathrm{d} D e p a r t m e n t}$ of Medical Cell Biology, Biomedical Center and ${ }^{\text {SSection of }}$ \\ Clinical Nutrition and Metabolism, Department of Public Health and Caring Sciences, Uppsala \\ University, and ${ }^{f}$ Cardiovascular Epidemiology, Department of Medical Sciences, Uppsala \\ University Hospital, Uppsala, and ${ }^{9}$ School of Health and Social Studies, Dalarna University, \\ Falun, Sweden
}

\section{Key Words}

Community $\cdot$ TNF- $\alpha \cdot$ Glomerular filtration $\cdot$ Albumin/creatinine ratio $\cdot$ Chronic kidney disease $\cdot$ Inflammation

\begin{abstract}
Objective: We aimed to explore and validate the longitudinal associations between soluble tumor necrosis factor receptor 1 (sTNFR1), glomerular filtration rate (GFR) progression, and chronic kidney disease (CKD) incidence in two independent community-based cohorts of elderly individuals with prespecified subgroup analyses in individuals without prevalent diabetes. Research Design and Methods: Two community-based cohorts of elderly individuals were used with 5-year follow-up data on estimated GFR: the Uppsala Longitudinal Study of Adult Men (ULSAM; $\mathrm{n}=437$ men; mean age: 78 years) and the Prospective Investigation of the Vasculature in Uppsala Seniors (PIVUS; $n=703$; mean age: 70 years; $51 \%$ women). GFR categories were defined as $\geq 60,30-60$, and $<30 \mathrm{ml} / \mathrm{min} / 1.73 \mathrm{~m}^{2}$. Results: In longitudinal multivariable logistic regression models adjusted for inflammatory markers and established cardiovascular risk factors, higher serum sTNFR1 was significantly associated with an increased risk to progress to a lower GFR category in both ULSAM and PIVUS [odds ratio (OR) per standard deviation (SD) increase 1.28 (95\% CI 1.03-1.60) and OR 1.56 (95\% CI 1.30-1.87), respec-
\end{abstract}




\section{CardioRenal Medicine}

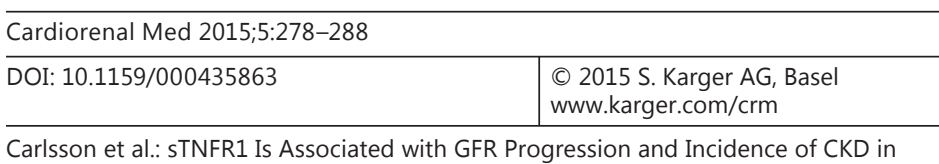

Two Community-Based Cohorts of Elderly Individuals

tively]. Also, in subgroup analyses in individuals with a GFR $\geq 60 \mathrm{ml} / \mathrm{min} / 1.73 \mathrm{~m}^{2}$ at baseline, higher sTNFRs were associated with incident CKD after 5 years in both cohorts [ULSAM: OR per SD increase 1.49 (95\% CI 1.16-1.9) and PIVUS: OR 1.84 (95\% CI 1.50-2.26)]. Associations were similar in individuals without diabetes. Conclusions: Higher circulating sTNFR1 independently predicts the progression to a worse GFR category and CKD incidence in elderly individuals even in the absence of diabetes. Further studies are warranted to investigate the underlying mechanisms, and to evaluate the clinical relevance of our findings.

(C) 2015 S. Karger AG, Base

\section{Introduction}

Soluble receptors for tumor necrosis factor (TNF)- $\alpha$ (sTNFRs) in plasma have been shown to be involved in inflammatory and stress response pathways, by blocking TNF- $\alpha$ from binding its target receptor [1] and thus also prolonging its effects. Yet, additional unique physiological responses of sTNFRs are present that are independent of TNF- $\alpha$ [2]. Moreover, sTNFR1 has repeatedly been shown to be associated with mortality in elderly individuals $[3,4]$.

Circulating sTNFRs have been reported to predict progression of chronic kidney disease (CKD) and development of end-stage renal disease in patients with diabetes $[5,6]$, providing additional support for previous experimental studies in rat models reporting a causal role for sTNFRs diabetic nephropathy [7]. Moreover, a causal link to diabetic nephropathy is further supported by studies in patients with diabetes showing that higher circulating sTNFRs are associated with an increased risk of progression of micro- to macro-albuminuria [8] as well as with a decline in estimated glomerular filtration rate (eGFR) in type 1 diabetes [9].

sTNFR1 as well as STNFR2 have been shown to be closely associated with glomerular filtration rate (GFR) and micro-albuminuria in a few community-based cross-sectional studies [10-13]. Yet, to date longitudinal community-based data on the association between sTNFRs and GFR progression are lacking.

We hypothesized that sTNFR1 plays a causal role in the development of kidney damage and dysfunction already at an early stage, prior to the development of CKD or diabetes. Accordingly, we aimed to explore and validate the longitudinal associations between STNFR1, GFR progression, and CKD incidence in two independent community-based cohorts of elderly individuals with prespecified subgroup analyses in individuals without diabetes.

\section{Methods}

Study Samples

The Prospective Investigation of the Vasculature in Uppsala Seniors

All 70-year-old men and women living in Uppsala, Sweden, between 2001 and 2004 were eligible for the Prospective Investigation of the Vasculature in Uppsala Seniors (PIVUS) study (described in detail on http://www.medsci.uu.se/pivus/pivus.htm) [14]. Of 2,025 invited individuals, 1,016 agreed to participate. A second examination cycle of the PIVUS was performed in 2006-2009 when participants were 75 years old. Of 964 invited subjects, 827 participated (86\%). Of these, 703 individuals had valid measurements of eGFR and sTNFR1 at baseline and follow-up.

The Uppsala Longitudinal Study of Adult Men

The Uppsala Longitudinal Study of Adult Men (ULSAM) was initiated in 1970. All 50-year-old men, born in 1920-1924 and living in Uppsala, Sweden, were invited to a health survey, focusing on identifying cardiovascular risk factors (described in detail on http://www.pubcare.uu.se/ULSAM ) [15]. The present study used the fourth examination cycle as baseline, when participants were approximately 77 years old (1998- 


\section{CardioRenal Medicine}

\begin{tabular}{l|l}
\hline Cardiorenal Med 2015;5:278-288 \\
\hline DOI: 10.1159/000435863 & $\begin{array}{l}\text { @ 2015 S. Karger AG, Basel } \\
\text { www.karger.com/crm }\end{array}$ \\
\hline
\end{tabular}

Carlsson et al.: sTNFR1 Is Associated with GFR Progression and Incidence of CKD in Two Community-Based Cohorts of Elderly Individuals

2001). Of 1,398 invited men, 838 (60\%) participated, and data on circulating levels of sTNFR1 were available in 786 individuals. We also used the 5th examination cycle (2003-2005) when participants were 82 years old in order to identify those who had progressed to CKD. To this examination, 952 men still living in Uppsala were invited and 530 men (56\%) participated in the investigation. After exclusion of individuals with missing data on sTNFR1 at baseline and individuals without data on eGFR at both examinations, 437 men comprised the present study sample.

Baseline Investigations

The investigations in PIVUS and ULSAM were performed using similar standardized methods, including anthropometrical measurements, blood pressure, blood sampling, and questionnaires regarding socioeconomic status, medical history, smoking habits, medication, and physical activity level [14, 15]. Venous blood samples were drawn in the morning after an overnight fast and stored at $-70^{\circ} \mathrm{C}$ until analysis.

In both cohorts, estimations of GFR were analyzed from serum cystatin $\mathrm{C}$ by latex-enhanced reagent (N Latex Cystatin C; Dade Behring, Deerfield, Ill., USA) using a BN ProSpec ${ }^{\circledR}$ analyzer (Dade Behring) with the formula: eGFR $=77.24 \times$ cystatin $C^{-1.2623}$ in ULSAM and using Gentian (Gentian, Moss, Norway) with the formula eGFR $=79.901 \times$ cystatin $\mathrm{C}^{-1.4389}$ in PIVUS. Both calculation formulas for eGFR are closely correlated with iohexol clearance $[16,17]$.

In both cohorts, sTNFR1 was analyzed using a commercially available ELISA kit (DY225; R\&D Systems, Minneapolis, Minn., USA). The assay had a total coefficient of variation of approximately $6 \%$.

In ULSAM, a 24-hour collection of urine was used, but no urine was collected at baseline in PIVUS. Urine albumin was measured by nephelometry (urine albumin, Dade Behring) using a Behring BN ProSpec ${ }^{\circledR}$ analyzer (Dade Behring). Urinary creatinine was analyzed with a modified kinetic Jaffe reaction on an Architect Ci8200 ${ }^{\circledR}$ analyzer (Abbott, Abbot Park, Ill., USA), and creatinine-related urine albumin (albumin/ creatinine ratio, ACR) was calculated.

Highly sensitive C-reactive protein (CRP) measurements were performed by latex-enhanced reagent (Siemens) with the use of a BN ProSpec analyzer (Siemens). Interleukin-6 (IL-6) was analyzed in serum using a high-sensitivity IL-6 assay (Quantikine HS ELISA Kit HS600; R\&D Systems) according to the instructions of the manufacturer in ULSAM, and with the Evidence ${ }^{\circledR}$ array biochip analyser (Randox Laboratories Ltd., Crumlin, UK) in PIVUS. Diabetes mellitus was diagnosed as fasting plasma glucose $\geq 7.0 \mathrm{mmol} / \mathrm{l}$ ( $\geq 126 \mathrm{mg}$ / $\mathrm{dl}$ ), or use of antidiabetic medication [18].

\section{GFR Progression and Incident CKD}

GFR was estimated at baseline and after 5 years. Progression of GFR was defined as progression from a higher to lower GFR group. The GFR categories were defined as $\geq 60,30-60$, and $<30 \mathrm{ml} / \mathrm{min} / 1.73 \mathrm{~m}^{2}$. Incidence of CKD was defined as having a GFR $<60 \mathrm{ml} / \mathrm{min} / 1.73 \mathrm{~m}^{2}$ after 5 years in individuals with a GFR $\geq 60$ $\mathrm{ml} / \mathrm{min} / 1.73 \mathrm{~m}^{2}$ at baseline.

\section{Statistical Analysis}

Multivariable logistic regression models were used to calculate odds ratios (OR) for progression to a lower GFR category and for incident CKD. In our primary analyses, we modelled sTNFR1 as per standard deviation (SD) increment. The following multivariable models were used:

- $\quad$ Model A: age (at the baseline and follow-up examination) and sex (PIVUS only).

- Model B: age at baseline and follow-up, sex (PIVUS), and inflammation (CRP and IL-6) to assure that sTNFR1 is independent of the most widely used inflammatory markers.

- Model C: age at baseline and follow-up and established cardiovascular risk factors (BMI, smoking, systolic blood pressure, high-density lipoprotein, cholesterol, diabetes, and antihypertensive and lipid treatment), as these factors are well-known kidney damage risk factors as well.

- Model D: all variables in models A-C combined.

- Model E: full model (all variables in model D with micro-albuminuria; only available in ULSAM).

In additional secondary models, we also added baseline GFR to model A. We also performed the above analyses in participants without diabetes.

As a secondary aim, Spearman correlation and linear regression models were used to estimate the association between change in sTNFR1 and change in eGFR over 5 years in the PIVUS cohort (data on STNFR1 were not available at the follow-up examination in ULSAM). Baseline GFR was included in all these models in order to limit the risk of regression towards the mean. SD changes in STNFR1 over 5 years were used as exposure variable in models A-D. 


\section{CardioRenal Medicine}

Table 1. Baseline characteristics of PIVUS and ULSAM

\begin{tabular}{l|l}
\hline \multicolumn{2}{l}{ Cardiorenal Med 2015;5:278-288 } \\
\hline DOI: $10.1159 / 000435863$ & $\begin{array}{l}\text { C } 2015 \text { S. Karger AG, Basel } \\
\text { www.karger.com/crm }\end{array}$ \\
\hline Carlsson et al.: sTNFR1 Is Associated with GFR Progression and Incidence of CKD in
\end{tabular}

Carlsson et al.: sTNFR1 Is Associated with GFR Progressio
Two Community-Based Cohorts of Elderly Individuals

\begin{tabular}{lcc}
\hline Variable & PIVUS & ULSAM \\
\hline Subjects, n & 703 & 437 \\
Female & $358(51)$ & 0 \\
Age, years & $70 \pm 0.2$ & $77.5 \pm 0.8$ \\
CRP, mg/l & $2.2 \pm 3.6$ & $3.9 \pm 7.5$ \\
sTNFR1, ng/l & $3,368 \pm 822$ & $1,975 \pm 663$ \\
IL-6, ng/l & $31 \pm 91$ & $3.7 \pm 2.6$ \\
eGFR, ml/min/1.73 m ${ }^{2}$ & $89 \pm 16$ & $76 \pm 15$ \\
ACR, mg/mmol & - & $2.7 \pm 9.8$ \\
BMI & $27 \pm 4$ & $26 \pm 3$ \\
Systolic blood pressure, mm Hg & $149 \pm 22$ & $150 \pm 20$ \\
Antihypertensive treatment & $210(30)$ & $191(44)$ \\
S-Cholesterol, mmol/l & $5.4 \pm 1.0$ & $5.4 \pm 1.0$ \\
High-density lipoprotein, mmol/l & $1.50 \pm 0.42$ & $1.3 \pm 0.3$ \\
Lipid-lowering treatment & $119(17)$ & $77(18)$ \\
Smoking & $62(9)$ & $25(6)$ \\
Cardiovascular disease & $113(16)$ & $109(25)$ \\
Diabetes & $58(8)$ & $52(12)$ \\
\hline
\end{tabular}

Data are mean \pm standard deviation for continuous variables and n (\%) for categorical variables.

We also investigated the association between sTNFR1 and percent of GFR decline in both cohorts. In these analyses, we also investigated the effect modification of baseline GFR on these associations using multiplicative interaction analyses. Multiple imputation methods were used to account for the potential influence of missing data. The statistical software package STATA 12.1 (StataCorp, College Station, Tex., USA) was used.

\section{Statement of Ethics}

All participants in PIVUS and ULSAM gave written informed consent and the Ethics Committee of Uppsala University approved the study protocols. Both studies were conducted according to the Declaration of Helsinki.

\section{Results}

The baseline characteristics of ULSAM and PIVUS are shown in table 1.

\section{GFR Progression}

Multivariable logistic regression models of the association between sTNFR1 and the odds of 5-year progression to a lower GFR category are shown in table 2. One SD higher serum STNFR1 was significantly associated with progression to a lower GFR category after the 5 -year follow-up in both cohorts. These results remained significant after adjustments for age at baseline and follow-up, sex, cardiovascular risk factors and CRP in both cohorts. In ULSAM, the association was still significant after adjusting for ACR (model E, $p<0.05$; data on ACR were not available in PIVUS). Interestingly, in this model in the ULSAM cohort, ACR did not predict CKD progression ( $\mathrm{p}=0.16$; data not shown in table). All findings in logistic regression models were similar when individuals with diabetes were excluded from the analyses (table 2). 
Carlsson et al.: sTNFR1 Is Associated with GFR Progression and Incidence of CKD in

Two Community-Based Cohorts of Elderly Individuals

Table 2. SD increments in STNFR1 and the associated odds of 5-year progression of CKD: logistic regression models

\begin{tabular}{|c|c|c|c|c|}
\hline & \multicolumn{2}{|l|}{ ULSAM } & \multicolumn{2}{|l|}{ PIVUS } \\
\hline & all individuals & $\begin{array}{l}\text { individuals without } \\
\text { diabetes }\end{array}$ & all individuals & $\begin{array}{l}\text { individuals without } \\
\text { diabetes }\end{array}$ \\
\hline Model A & $1.24(1.01-1.53)^{*}$ & $1.31(1.04-1.63)^{*}$ & $1.72(1.45-2.04)^{* * *}$ & $1.73(1.44-2.07)^{* * *}$ \\
\hline Model B & $1.26(1.02-1.56)^{*}$ & $1.26(1.02-1.56)^{*}$ & $1.73(1.46-2.06)^{* * *}$ & $1.73(1.44-2.08)^{* * *}$ \\
\hline Model C & $1.27(1.02-1.58)^{*}$ & $1.32(1.05-1.65)^{*}$ & $1.55(1.29-2.85)^{* * *}$ & $1.56(1.29-1.89)^{* * *}$ \\
\hline Model D & $1.28(1.03-1.60)^{*}$ & $1.34(1.06-1.69)^{*}$ & $1.56(1.30-1.87)^{* * *}$ & $1.57(1.29-2.90)^{* * *}$ \\
\hline Model E & $1.29(1.03-1.61)^{*}$ & $1.34(1.06-1.69)^{*}$ & No data & No data \\
\hline
\end{tabular}

Values are OR (95\% CI). For the adjustments made in the models, see Statistical Analysis section.

Significance level: ${ }^{*} \mathrm{p}<0.05,{ }^{* * *} \mathrm{p}<0.001$.

Table 3. SD increments in sTNFR1 and the associated odds of 5-year incidence of CKD: logistic regression models

\begin{tabular}{llllll}
\hline & ULSAM & & PIVUS & \\
\cline { 2 - 3 } \cline { 5 - 6 } & all individuals & $\begin{array}{l}\text { individuals without } \\
\text { diabetes }\end{array}$ & & all individuals & \multicolumn{1}{c}{$\begin{array}{l}\text { individuals without } \\
\text { diabetes }\end{array}$} \\
\hline Model A & $1.46(1.15-1.86)^{* *}$ & $1.53(1.18-1.97)^{* *}$ & & $2.03(1.67-2.46)^{* * *}$ & $1.98(1.61-2.42)^{* * *}$ \\
Model B & $1.46(1.14-1.86)^{* *}$ & $1.53(1.18-1.98)^{* *}$ & & $2.04(1.68-2.48)^{* * *}$ & $1.98(1.61-2.43)^{* * *}$ \\
Model C & $1.49(1.16-1.91)^{* *}$ & $1.53(1.18-1.99)^{* *}$ & & $1.82(1.49-2.23)^{* * *}$ & $1.77(1.44-2.19)^{* * *}$ \\
Model D & $1.49(1.16-1.91)^{* *}$ & $1.53(1.18-2.00)^{* *}$ & & $1.84(1.50-2.26)^{* * *}$ & $1.79(1.44-2.21)^{* * *}$ \\
Model E & $1.49(1.16-1.92)^{* *}$ & $1.53(1.18-2.00)^{* *}$ & & No data & No data \\
\hline
\end{tabular}

Values are OR (95\% CI). For the adjustments made in the models, see Statistical Analysis section.

Significance level: $* * \mathrm{p}<0.01,{ }^{* * *} \mathrm{p}<0.001$.

\section{CKD Incidence}

Multivariable logistic regression models of the association between STNFR1 and the odds of 5-year incidence of CKD (GFR $<60 \mathrm{ml} / \mathrm{min} / 1.73 \mathrm{~m}^{2}$ ) in individuals with a GFR $\geq 60 \mathrm{ml}$ / $\mathrm{min} / 1.73 \mathrm{~m}^{2}$ are shown in table 3 . One SD higher serum sTNFR1 was significantly associated with incident CKD in both cohorts. These results remained significant after adjustments for age at baseline and follow-up, sex, cardiovascular risk factors, CRP, and IL-6 in both cohorts. In ULSAM, the association between STNFR1 and the risk for CKD was still significant after adjusting for ACR (model $\mathrm{E}, \mathrm{p}<0.01$ ). In this model in the ULSAM cohort, ACR did not predict CKD progression ( $p=0.27$; data not shown in table). Further addition of baseline GFR to model A attenuated the association between STNFR1 and CKD incidence but was still significant in PIVUS [PIVUS: OR per SD increase of sTNFR1 1.25 (95\% CI 1.00-1.56), $\mathrm{p}<0.05$, and ULSAM: 1.08 (95\% CI 0.83-1.42), $\mathrm{p}=0.57$ ]. All findings in logistic regression models were similar when individuals with diabetes were excluded from the analyses (table 3 ).

\section{Longitudinal Change in sTNFR1 and GFR}

As a secondary aim, we investigated the association between change in serum sTNFR1 and change in GFR over 5 years in linear regression models. The association was significant 


\section{CardioRenal Medicine}

Table 4. The linear association between change in circulating sTNFR1 and change in GFR over 5 years of follow-up in the PIVUS cohort: multivariable linear regression models

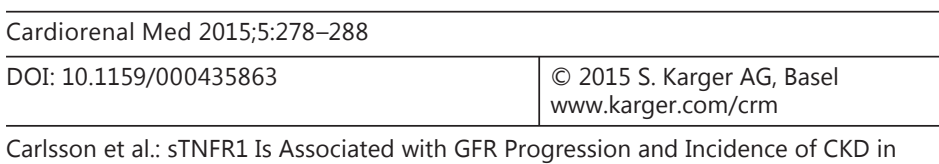

Carlsson et al.: sTNFR1 Is Associated with GFR Progression and Incidence of CKD in Two Community-Based Cohorts of Elderly Individuals

\begin{tabular}{ll}
\hline & Regression coefficients $(95 \% \mathrm{CI})$ \\
\hline Model A & $-0.002(-0.002,-0.001)^{* * *}$ \\
Model B & $-0.002(-0.002,-0.001)^{* * *}$ \\
Model C & $-0.002(-0.002,-0.001)^{* * *}$ \\
Model D & $-0.002(-0.002,-0.001)^{* * *}$ \\
\hline
\end{tabular}

For the adjustments made in the models, see Statistical Analysis section. Significance level: ${ }^{* * *} \mathrm{p}<0.001$.

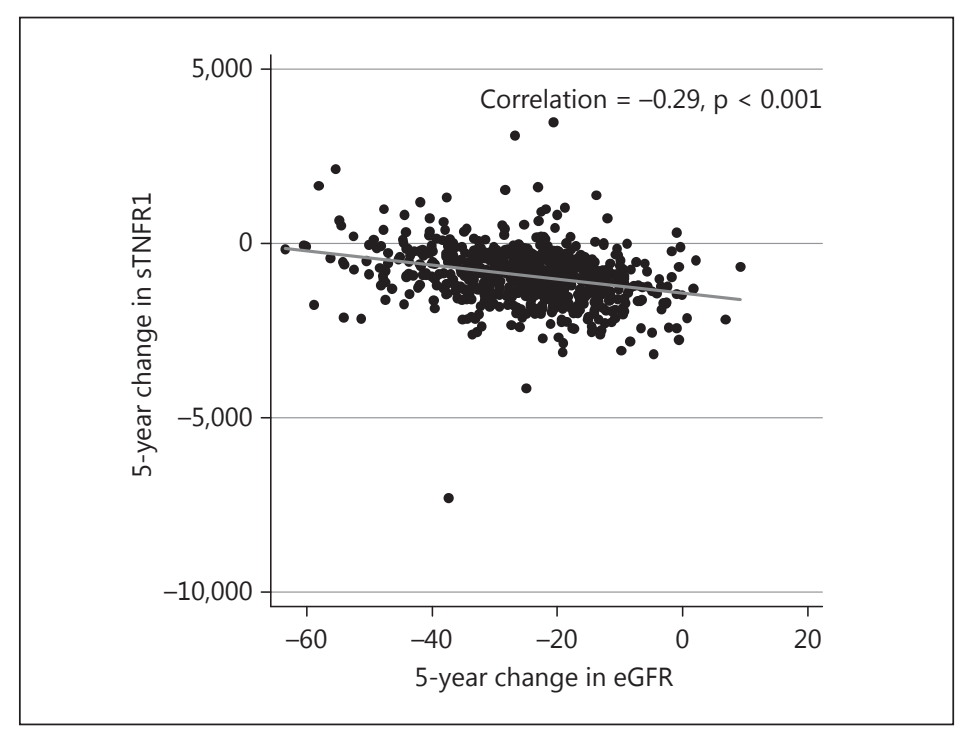

Fig. 1. The association between 5-year changes in sTNFR1 and 5 -year changes in eGFR. 
Carlsson et al.: sTNFR1 Is Associated with GFR Progression and Incidence of CKD in Two Community-Based Cohorts of Elderly Individuals

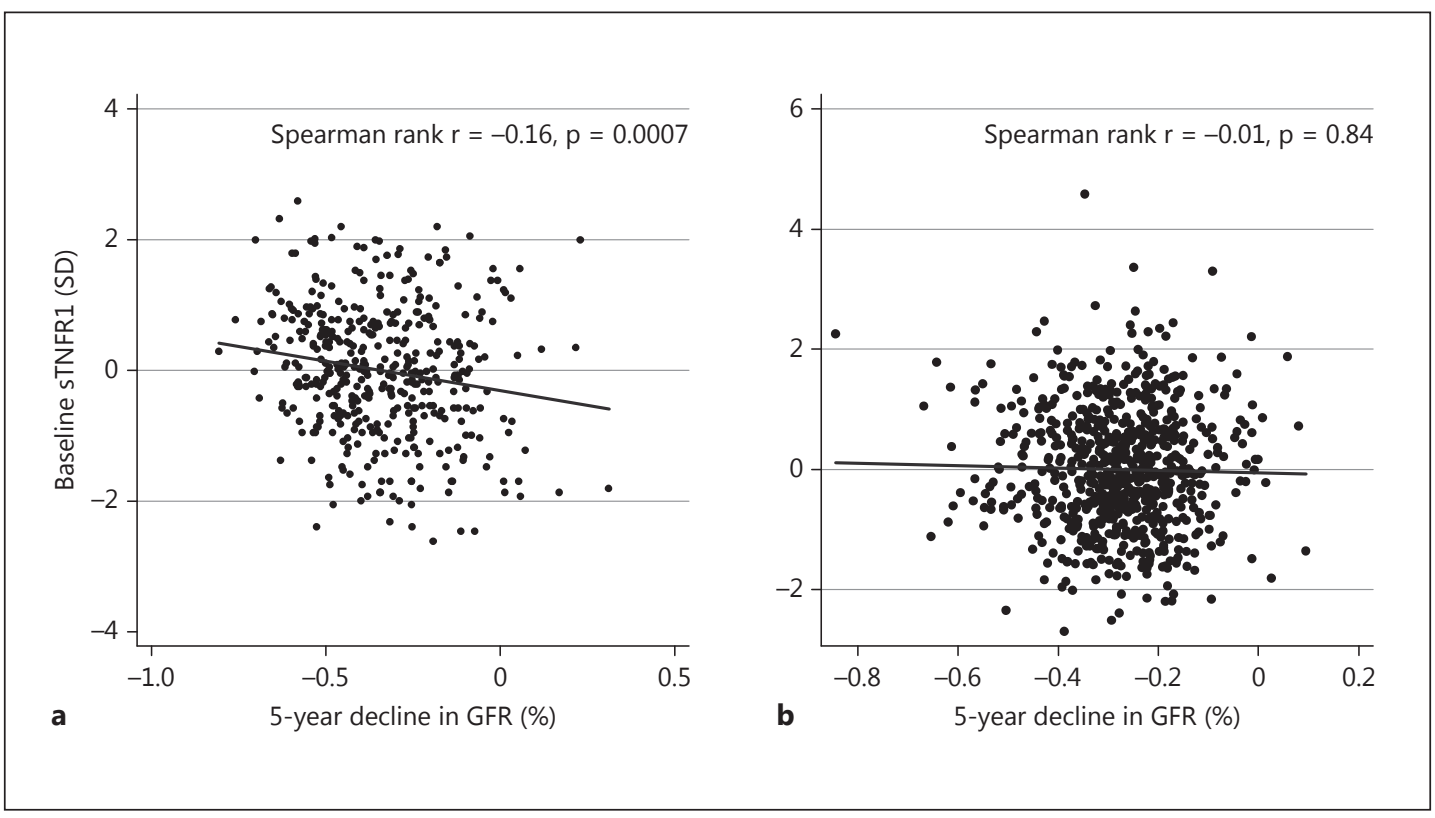

Fig. 2. The association between baseline levels of sTNFR1 and 5-year decline in GFR in ULSAM (a) and PIVUS (b).

This association was independent of cardiovascular risk factors, inflammatory markers, and ACR. In the ULSAM cohort, baseline sTNFR1 also predicted relative GFR decline independently of baseline GFR, and in the PIVUS cohort there was a close association between longitudinal changes in STNFR1 and changes in GFR over 5 years.

\section{Comparisons with Previous Studies}

The present longitudinal community-based data are in accordance with studies in patients with diabetes reporting that higher sTNFRs are associated with deterioration of kidney function $[5,9,19]$. One study in patients with diabetes reported that sTNFRs are superior to many inflammatory markers including IL- 6 and TNF- $\alpha$ as prognostic markers of eGFR decline [9], which is in accordance with our data on elderly individuals (mostly without diabetes), where adjustments for IL-6 and CRP had little influence on the sTNFR1 point estimates. Moreover, sTNFRs have repeatedly been shown to be linked to kidney dysfunction and micro-albuminuria $[8,9]$, both as direct mediators of kidney damage and as markers of an underpinning TNF- $\alpha$ activity [20]. However, we are aware of no previous studies reporting the association between circulating sTNFR1 and CKD incidence in the community-based setting, or in individuals without diabetes.

\section{Possible Mechanisms for Observed Associations}

Several potential mechanisms may help explain a causal association between sTNFR1 and CKD progression. sTNFRs appear to be involved in nephropathy, and particularly tubulointerstitial fibrosis [21]. Moreover, sTNFR1 increases the risk of CKD in diabetic patients [5, $6,19]$, and high levels of sTNFR1 are associated with development of end-stage renal disease inflammation $[6,8,9]$, mediated through IL-1, IL-6, and IL-18. TNF- $\alpha$ has also been associated with kidney pathogenesis and progression of CKD [22]. A possible mechanism is that TNFRs, directly or through TNF- $\alpha$ pathway activation, accelerate GFR decline through an increase in inflammation and apoptosis [23]. The finding in the present study that sTNFR1 was asso- 


\section{CardioRenal Medicine}

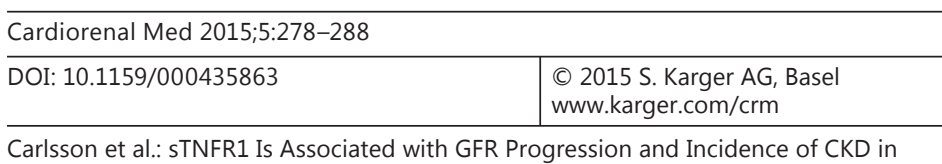

Carlsson et al.: STNFR1 Is Associated with GFR Progressid
Two Community-Based Cohorts of Elderly Individuals

ciated with CKD incidence after adjustments for IL-6 and CRP indicates that sTNFR1 represents an independent inflammatory pathway.

Oxidative stress and/or oxygenation also appear to play a part in STNFR1 action. sTNFR1 knockout mice have been reported to less likely develop kidney injury after an ischemiareperfusion insult [24]. In addition, it has recently been shown that TNFR1 knockout mice are protected against GFR decline, albuminuria, and glomerular endothelial injury after treatment with inflammatory endotoxin [24]. In that same study, intravenous administration of TNF would decrease GFR and induce fenestrae loss, increase fenestrae diameter, and injure the glomerular endothelium.

As of yet, it is unknown what triggers the increase in STNFR1 in patients. Oxidative stress may increase TNF- $\alpha$ activity and likely contribute to the progression of CKD in diabetic nephropathy [21]. sTNFR1 has been reported to correlate with GFR in diabetic patients with early diabetic nephropathy [25]. In our study, sTNFR1 was associated with progression of GFR and CKD incidence in elderly individuals without diabetes, indicating that hyperglycemia is not the sole driver of the sTNFR1-associated decline in eGFR.

The elevation of sTNFR1 could also be a consequence of aging-induced hypoxia. Renal tissue hypoxia and adenosine triphosphate starvation have been suggested as a common pathway for the development of kidney injury and progression to CKD, mainly by inducing extracellular matrix production, collagen deposition, and tubulointerstitial fibrosis. Recently, it has been shown that kidney hypoxia will induce nephropathy independently of hyperglycemia and oxidative stress [26]. Renal aging has been associated with hypoxia, correlating with tubulointerstitial injury and peritubular capillary loss (and increase of hypoxia-inducible factor response) [27]. Since sTNFR1, TNF- $\alpha$, and oxidative stress will all increase in rats exposed to intermittent hypoxia [28], and TNFRs have been implicated in tubulointerstitial fibrosis [21], sTNFR may be a key factor in GFR decline in the aging kidney.

sTNFR1-driven development of atherosclerosis in the kidneys may also deteriorate kidney function [29]. However, when adjusted for established risk factors for cardiovascular disease, little effects were seen on the risk estimates in this study, suggesting that atherosclerosis is not a main inducer of the present associations.

Also, since TNF- $\alpha$ activity may be induced by malnutrition [30], poor diet in the elderly individuals in our study may have contributed to the decline in GFR. It could also be a case of reverse causation, where the loss of kidney function may have induced a loss of appetite and resulted in a higher sTNFR activity.

Finally, since TNFRs are eliminated mainly by the kidneys, it cannot be ruled out that increased circulating concentrations may be the result from a declining GFR, i.e. that our results are due to reverse causation. The pathological relevance of sTNFR1 in the aging kidney calls for further investigation.

\section{Clinical Implications}

The worldwide prevalence of CKD is about 10\% [31], and methods to limit its impact on overall health in the population are warranted. sTNFR1 have been put forward as a promising biomarker for diabetic nephropathy but our study suggest that there may be implications for sTNFR1 also in nondiabetic kidney disease. Yet, studies of the clinical utility of sTNFR measurements and how to best intervene in individuals with elevated sTNFRs are scarce. Interestingly, CKD progression and kidney function decline have been shown to be inhibited with recombinant antibodies against TNF- $\alpha$ [32-34], and micro-albuminuria has been shown to be reduced in rats treated with TNF- $\alpha$ inhibitors [35]. The TNF- $\alpha$ inhibitors have been suggested to be safe in patients with acute kidney failure treated for rheumatoid arthritis [36]; yet, we warrant clinical studies in humans to elucidate if anti-TNF therapy can also halt CKD progression and micro-albuminuria, and if levels of sTNFR1 can be used to monitor these effects. 


\section{CardioRenal Medicine}

\begin{tabular}{l|l}
\hline Cardiorenal Med 2015;5:278-288 \\
\hline DOI: 10.1159/000435863 & $\begin{array}{l}\text { @ } 2015 \text { S. Karger AG, Basel } \\
\text { www.karger.com/crm }\end{array}$ \\
\hline
\end{tabular}

Carlsson et al.: sTNFR1 Is Associated with GFR Progression and Incidence of CKD in Two Community-Based Cohorts of Elderly Individuals

\section{Strengths and Limitations}

The strengths of our investigation include the longitudinal study design, the validation of our findings in an independent cohort, and the detailed characterization of the study participants. To our knowledge, PIVUS is the largest cohort with repeated sTNFR1 measurements to date. The fact that the longitudinal changes in sTNFR1 were significantly associated with longitudinal changes in GFR over a 5-year period adds additional support for the theory of a causal association. Further studies are needed to shed light on this issue.

Limitations include the unknown generalizability to other age and ethnic groups. Moreover, in ULSAM but not in PIVUS, the longitudinal association between STNFR1 and the risk for CKD incidence was attenuated after adjusting for baseline GFR. However, adjustment for baseline GFR may represent an 'overadjustment' as GFR is cross-sectionally related to sTNFR1 [10] and may therefore represent an intermediate state along the causal pathway from sTNFR1 leading to CKD. Another limitation is the fact that no longitudinal data on ACR were available in any cohort. Finally, we cannot rule out that the association is to some extent explained by residual confounding by uncontrolled factors.

In conclusion, higher circulating sTNFR1 independently predicts GFR progression and CKD incidence in elderly individuals. Further studies are warranted to investigate the underlying mechanisms as well as the clinical relevance of our findings.

\section{Acknowledgements}

This study was supported by the Swedish Research Council, Swedish Heart-Lung Foundation, Thuréus Foundation, the Marianne and Marcus Wallenberg Foundation, Dalarna University, and Uppsala University. The funding sources did not play any role in the design and conduct of the study; the collection, management, analysis, and interpretation of the data, and the preparation, review, or approval of the manuscript. Dr. Ärnlöv is the guarantor of this work, had full access to all the data, and takes full responsibility for the integrity of the data and the accuracy of data analysis.

\section{Disclosure Statement}

The authors have no conflicts of interest to disclose.

\section{References}

1 Pass HI, Mew D, Pass HA, Temeck BK: The macrophage, TNF, and other cytokines. Chest Surg Clin N Am 1995; 5:73-90.

2 Cabal-Hierro L, Lazo PS: Signal transduction by tumor necrosis factor receptors. Cell Signal 2012;24:12971305.

3 Carlsson AC, Juhlin CC, Larsson TE, Larsson A, Ingelsson E, Sundstrom J, Lind L, Arnlov J: Soluble tumor necrosis factor receptor 1 (sTNFR1) is associated with increased total mortality due to cancer and cardiovascular causes - findings from two community based cohorts of elderly. Atherosclerosis 2014;237:236-242.

4 Luna JM, Moon Y, Liu K, Spitalnik S, Paik M, Sacco R, Elkind MS: Tumour necrosis factor receptor 1 and mortality in a multi-ethnic cohort: the Northern Manhattan Study. Age Ageing 2013;42:385-390.

-5 Gohda T, Niewczas MA, Ficociello LH, Walker WH, Skupien J, Rosetti F, Cullere X, Johnson AC, Crabtree G, Smiles AM, Mayadas TN, Warram JH, Krolewski AS: Circulating TNF receptors 1 and 2 predict stage 3 CKD in type 1 diabetes. J Am Soc Nephrol 2012;23:516-524.

6 Niewczas MA, Gohda T, Skupien J, Smiles AM, Walker WH, Rosetti F, Cullere X, Eckfeldt JH, Doria A, Mayadas TN, Warram JH, Krolewski AS: Circulating TNF receptors 1 and 2 predict ESRD in type 2 diabetes. J Am Soc Nephrol 2012;23:507-515.

7 Hasegawa G, Nakano K, Sawada M, Uno K, Shibayama Y, Ienaga K, Kondo M: Possible role of tumor necrosis factor and interleukin-1 in the development of diabetic nephropathy. Kidney Int 1991;40:1007-1012. 


\section{CardioRenal Medicine}

\begin{tabular}{l|l}
\hline \multicolumn{2}{l}{ Cardiorenal Med 2015;5:278-288 } \\
\hline DOI: $10.1159 / 000435863$ & $\begin{array}{l}\text { C 2015 S. Karger AG, Basel } \\
\text { www.karger.com/crm }\end{array}$ \\
\hline
\end{tabular}

Carlsson et al.: sTNFR1 Is Associated with GFR Progression and Incidence of CKD in

Two Community-Based Cohorts of Elderly Individuals

-8 Lopes-Virella MF, Baker NL, Hunt KJ, Cleary PA, Klein R, Virella G: Baseline markers of inflammation are associated with progression to macroalbuminuria in type 1 diabetic subjects. Diabetes Care 2013;36:2317-2323.

-9 Krolewski AS, Niewczas MA, Skupien J, Gohda T, Smiles A, Eckfeldt JH, Doria A, Warram JH: Early progressive renal decline precedes the onset of microalbuminuria and its progression to macroalbuminuria. Diabetes Care 2014;37:226-234.

-10 Carlsson AC, Larsson TE, Helmersson-Karlqvist J, Larsson A, Lind L, Arnlov J: Soluble TNF receptors and kidney dysfunction in the elderly. J Am Soc Nephrol 2014;25:1313-1320.

11 Keller C, Katz R, Cushman M, Fried LF, Shlipak M: Association of kidney function with inflammatory and procoagulant markers in a diverse cohort: a cross-sectional analysis from the Multi-Ethnic Study of Atherosclerosis (MESA). BMC Nephrol 2008;9:9.

$\checkmark 12$ Keller CR, Odden MC, Fried LF, Newman AB, Angleman S, Green CA, Cummings SR, Harris TB, Shlipak MG: Kidney function and markers of inflammation in elderly persons without chronic kidney disease: the health, aging, and body composition study. Kidney Int 2007;71:239-244.

-13 Upadhyay A, Larson MG, Guo CY, Vasan RS, Lipinska I, O’Donnell CJ, Kathiresan S, Meigs JB, Keaney JF Jr, Rong J, Benjamin EJ, Fox CS: Inflammation, kidney function and albuminuria in the Framingham Offspring cohort. Nephrol Dial Transplant 2011;26:920-926.

14 Lind L, Fors N, Hall J, Marttala K, Stenborg A: A comparison of three different methods to evaluate endothelium-dependent vasodilation in the elderly: the Prospective Investigation of the Vasculature in Uppsala Seniors (PIVUS) study. Arterioscler Thromb Vasc Biol 2005;25:2368-2375.

15 Helmersson J, Vessby B, Larsson A, Basu S: Association of type 2 diabetes with cyclooxygenase-mediated inflammation and oxidative stress in an elderly population. Circulation 2004;109:1729-1734.

-16 Flodin M, Jonsson AS, Hansson LO, Danielsson LA, Larsson A: Evaluation of Gentian cystatin C reagent on Abbott Ci8200 and calculation of glomerular filtration rate expressed in $\mathrm{ml} / \mathrm{min} / 1.73 \mathrm{~m}^{2}$ from the cystatin C values in mg/l. Scand J Clin Lab Invest 2007;67:560-567.

$\checkmark 17$ Larsson A, Malm J, Grubb A, Hansson LO: Calculation of glomerular filtration rate expressed in $\mathrm{ml} / \mathrm{min}$ from plasma cystatin c values in mg/l. Scand J Clin Lab Invest 2004;64:25-30.

-18 Wandell PE, Carlsson AC, de Faire U, Hellenius ML: Prevalence of blood lipid disturbances in Swedish and foreign-born 60-year-old men and women in Stockholm, Sweden. Nutr Metab Cardiovasc Dis 2011;21:173181.

19 Miyazawa I, Araki S, Obata T, Yoshizaki T, Morino K, Kadota A, Ugi S, Kawai H, Uzu T, Nishio Y, Koya D, Haneda M, Kashiwagi A, Maegawa H: Association between serum soluble TNF $\alpha$ receptors and renal dysfunction in type 2 diabetic patients without proteinuria. Diabetes Res Clin Pract 2011;92:174-180.

20 Aderka D, Engelmann H, Maor Y, Brakebusch C, Wallach D: Stabilization of the bioactivity of tumor necrosis factor by its soluble receptors. J Exp Med 1992;175:323-329.

21 Guo G, Morrissey J, McCracken R, Tolley T, Klahr S: Role of TNFR1 and TNFR2 receptors in tubulointerstitial fibrosis of obstructive nephropathy. Am J Physiol 1999;277:F766-F772.

22 Navarro-Gonzalez JF, Mora-Fernandez C: The role of inflammatory cytokines in diabetic nephropathy. J Am Soc Nephrol 2008;19:433-442.

23 Al-Lamki RS, Wang J, Vandenabeele P, Bradley JA, Thiru S, Luo D, Min W, Pober JS, Bradley JR: TNFR1- and TNFR2-mediated signaling pathways in human kidney are cell type-specific and differentially contribute to renal injury. FASEB J 2005;19:1637-1645.

24 Di Paola R, Genovese T, Impellizzeri D, Ahmad A, Cuzzocrea S, Esposito E: The renal injury and inflammation caused by ischemia-reperfusion are reduced by genetic inhibition of TNF- $\alpha$ R1: a comparison with infliximab treatment. Eur J Pharmacol 2013;700:134-146.

-25 Niewczas MA, Ficociello LH, Johnson AC, Walker W, Rosolowsky ET, Roshan B, Warram JH, Krolewski AS: Serum concentrations of markers of TNFalpha and Fas-mediated pathways and renal function in nonproteinuric patients with type 1 diabetes. Clin J Am Soc Nephrol 2009;4:62-70.

-26 Friederich-Persson M, Thorn E, Hansell P, Nangaku M, Levin M, Palm F: Kidney hypoxia, attributable to increased oxygen consumption, induces nephropathy independently of hyperglycemia and oxidative stress. Hypertension 2013;62:914-919.

27 Tanaka T, Kato H, Kojima I, Ohse T, Son D, Tawakami T, Yatagawa T, Inagi R, Fujita T, Nangaku M: Hypoxia and expression of hypoxia-inducible factor in the aging kidney. J Gerontol A Biol Sci Med Sci 2006;61:795-805.

-28 Lam SY, Liu Y, Ng KM, Lau CF, Liong EC, Tipoe GL, Fung ML: Chronic intermittent hypoxia induces local inflammation of the rat carotid body via functional upregulation of proinflammatory cytokine pathways. Histochem Cell Biol 2012;137:303-317.

29 Svenungsson E, Fei GZ, Jensen-Urstad K, de Faire U, Hamsten A, Frostegard J: TNF-alpha: A link between hypertriglyceridaemia and inflammation in SLE patients with cardiovascular disease. Lupus 2003;12:454-461.

-30 Pitsiou G, Kyriazis G, Hatzizisi O, Argyropoulou P, Mavrofridis E, Patakas D: Tumor necrosis factor-alpha serum levels, weight loss and tissue oxygenation in chronic obstructive pulmonary disease. Respir Med 2002; 96:594-598.

-31 Hallan SI, Coresh J, Astor BC, Asberg A, Powe NR, Romundstad S, Hallan HA, Lydersen S, Holmen J: International comparison of the relationship of chronic kidney disease prevalence and ESRD risk. J Am Soc Nephrol 2006;17:2275-2284. 
-32 Doria A, Niewczas MA, Fiorina P: Can existing drugs approved for other indications retard renal function decline in patients with type 1 diabetes and nephropathy? Semin Nephrol 2012;32:437-444.

-33 Elmarakby AA, Quigley JE, Pollock DM, Imig JD: Tumor necrosis factor alpha blockade increases renal Cyp2c23 expression and slows the progression of renal damage in salt-sensitive hypertension. Hypertension 2006;47: 557-562.

-34 Muller DN, Shagdarsuren E, Park JK, Dechend R, Mervaala E, Hampich F, Fiebeler A, Ju X, Finckenberg P, Theuer J, Viedt C, Kreuzer J, Heidecke H, Haller H, Zenke M, Luft FC: Immunosuppressive treatment protects against angiotensin ii-induced renal damage. Am J Pathol 2002;161:1679-1693.

-35 Moriwaki Y, Inokuchi T, Yamamoto A, Ka T, Tsutsumi Z, Takahashi S, Yamamoto T: Effect of TNF-alpha inhibition on urinary albumin excretion in experimental diabetic rats. Acta Diabetol 2007;44:215-218.

-36 Cho SK, Sung YK, Park S, Bae SC: Etanercept treatment in rheumatoid arthritis patients with chronic kidney failure on predialysis. Rheumatol Int 2010;30:1519-1522. 